\title{
The Demand for Crop Insurance Bundled with Micro-Credit
}

\author{
Mame Mor Anta Syll 1,2 \\ ${ }^{1}$ University Gaston Berger (UGB), Saint-Louis, Senegal \\ ${ }^{2}$ Initiative Prospective Agricole et Rurale (IPAR, Think Tank), Dakar, Senegal \\ Email: mamemorantasyll@gmail.com
}

How to cite this paper: Syll, M. M. A. (2021). The Demand for Crop Insurance Bundled with Micro-Credit. Theoretical Economics Letters, 11, 889-909.

https://doi.org/10.4236/tel.2021.115057

Received: August 16, 2021

Accepted: September 27, 2021

Published: September 30, 2021

Copyright $\odot 2021$ by author(s) and Scientific Research Publishing Inc. This work is licensed under the Creative Commons Attribution International License (CC BY 4.0).

http://creativecommons.org/licenses/by/4.0/

\begin{abstract}
Access to financial services is challenging for small farmers in developing countries. This paper studies the demand for micro-insurance when it is bundled with micro-credit in the context of rain-fed agriculture. It presents the conditions under which linking micro-insurance with micro-credit can be beneficial for small producers who cannot access agricultural credit due to lack of collateral. The results show that if crop insurance and agricultural loans are bundled, the demand for crop insurance increases with the profitability of the investment made through the agricultural credit, and it decreases with the level of collateral required during the application for credit.
\end{abstract}

\section{Keywords}

Micro-Insurance, Agricultural Micro-Credit, Finance, Demand

\section{Introduction}

Microfinance provides a large range of financial services to people who would have difficulties accessing conventional banks. Those financial services include microcredit, micro-savings, micro-insurance, micro money-transfers, etc. Micro-insurance enables populations excluded from the traditional financial system to protect against the risks weighing on their person, their property, or their activities. In the agricultural sector, weather index-based (micro)-insurance (WII) is an innovative micro-insurance product allowing farmers without access to the traditional financial systems to protect against agricultural risks. It is innovative insofar as unlike traditional crop insurance, compensation is triggered by indices that are correlated with the damage so that their simple monitoring makes it possible to have legibility of claims and trigger the compensations. 
According to Roberts (2005), in 2001, the global premiums of agricultural insurance were evaluated at 6.5 billion USD and developing countries represented only $13 \%$ of the total amount. To increase the uptake of agricultural insurance products, practitioners and policymakers, along with the researchers committed to the development of weather index-based insurance products in replacement of traditional crop insurance that failed to scale-up. However, empirical results related to the demand of WII revealed modest voluntary take-up rates after two decades of experiments (Giné and Yang, 2008; Cole et al., 2013; Giné and Yang, 2009). Hill, Ruth, \& Robles (2011), recall that only $10 \%$ in average of the potential clients of WII are buying the product. Matul et al. (2013) add the fact that even for the contracts that are largely subsidized, the take-up rates are barely above $30 \%$ with exceptionally modest renewal rates.

To understand the enigma of that low performance, an important empirical literature grew up around the question of the determinants of the demand (see Marr et al., 2016; Eling et al., 2014, for a complete literature review). That is how basis risk (Clarke, 2016; Collier et al., 2009; Hazel et al., 2010; The World-Bank, 2009), contractual non-performance, (Doherty and Shlesinger, 1990; Jensen et al., 2014), trust (Dercon et al., 2019), or understanding (Takahashi et al., 2016) have been presented as potential constraints to the demand. Micro-credit has been also presented as either a substitute to micro-insurance (Giné and Yang, 2009; Liu and Myers, 2012; Zimmerman et al., 2016) or a complement to it (Carter et al., 2011; Jensen et al., 2014). Next to all of this abundant empirical literature the theoretical literature continues to play its traditional role of pathfinder. Clarke (2016) explained in his model how basis risk makes the rational demand for WII absent. Gollier (2003) and Liu and Myers (2012) put in relation the demand and the liquidity constraints faced by the farmers with the first author supporting the idea that it increases the demand while the second authors say that it does not. On the relationship with micro-credit, Carter et al. (2011) show that wealthier farmers who can provide high amount of collateral purchase insurance to protect their collateral while less wealthy farmers with little collateral to loose decide to insure only if the price of the credit is low.

In the context of rain-fed agriculture which characterizes the developing countries such as West African countries where the farmers have often only one rainy season as regular production period and hence as main regular source of income, what are the conditions under which agricultural micro-credit could boost the purchase of crop insurance through bundling? We contributed to the literature by providing an answer to that question through theoretical results which showed a positive relationship between the demand for crop WII and agricultural credit. We demonstrated that the demand for crop insurance at the moment of application for an agricultural credit increases with the profitability of the credit of the previous season and decreases with the amount of collateral requested during the loan application. In the remaining of the paper, we present first the theoretical literature, then we introduce the model before discussing its 
findings and concluding.

\section{Review of the Theoretical Literature on the Demand for Crop Micro-Insurance}

The theoretical works on the relation between micro-insurance and micro-credit in the agricultural sector can be organized into two groups of findings. In one side, there are findings that highlight the obstacles that liquidity constraints represents for the demand of crop micro-insurance and on the other side, the capacity of micro-credit to unlock take-up of crop insurance when the farmers have access to both of them has been demonstrated.

\subsection{Credit Constraints as a Barrier to Index Insurance Demand}

Among the theoretical results that have highlighted the effect of liquidity constraints and access to credit on demand, that of Clarke (2016) is among the most famous. Clarke starts from the classical model of insurance demand of Mossin (1968) to then take into account the risk of contractual default of the insurer introduced for the first time by Doherty and Shlesinger (1990), but considering that the default would come this time from basis risk. He finds that in this context, mainly because the basis risks creates more uncertainty around the insurance product by adding two more states of nature (the possibility of being stricken without being reimbursed and the possibility of being compensated without disaster), the optimal demand for producers who are risk averse is zero. Clarke did not work in a context of coupling insurance with credit. But he finds that even in a context of access to credit his results remain valid.

On the other hand, in the theoretical model of Gollier (2003), only households that face liquidity constraints or too much risk of damage such as disasters agree to insure themselves. His results stem from a dynamic two-regime model. In the first regime, which is a self-insurance plan, the individual accumulates enough resources to self-insure because he is in a hurry to get rid of the external insurance. It does everything to accumulate more wealth over time and diversify the risks it faces. In the second regime, which is the external insurance plan, individuals do not seek to accumulate wealth over time, this is the case when the rate of impatience is sufficiently higher than the interest rate, when the insurance premium is affordable, or when risk aversion is high.

Liu and Myers (2012) took the same direction as Gollier (2003) by also developing a dynamic model that takes into account the liquidity constraints, but they found an opposite result after enriching the model by taking into account the risk of default of the insurer. They found that the existence of liquidity constraints reduces the demand for index insurance in the absence of the risk of default and even when the actuarial premium is fair. When the risk of default is introduced, the absence of a liquidity constraint and the fair premium result in a drop in demand because, whatever the amount of the premium, it may be lost in the event of default. Liu and Myers (2012) went further in their work by pro- 
posing an alternative model for which farmers can delay the payment of the premium until the end of the period covered by the insurance contract. They found that postponing the payment of the premium, which means that it is pre-financed with the credit, relaxes the liquidity constraints that prevent the underwriting of insurance.

\subsection{Linking Index Insurance with Agricultural Credit to Boost Demand}

Carter et al. (2011) have developed the theoretical model that is the closest to our work by linking index insurance demand and access to credit according to the level of collateral. They consider in their model three types of insurance: self-insurance, implicit insurance through a credit and finally a formal insurance contract. Their results show that farmers with a high level of collateral do not accept taking credit in the absence of a formal insurance contract because they avoid putting their collateral at risk. For this type of farmers, formal insurance dominates implicit insurance through access to credit and they are willing to pay the premium.

On the other hand, farmers with a low level of collateral agree to subscribe only if the interest rate of the credit is low. Indeed, these small producers have a low level of collateral and therefore the risk of losing it is not a major obstacle for them. Buying an insurance contract gives them a small additional profit but is very beneficial for their lender. The level of collateral held by the farmer thus occupies an important place in this context because those with a high level of collateral are rationed in terms of risks in the absence of formal insurance and farmers with a low level of collateral are rationed in terms of prices if they cannot afford to pay a high interest rate on the credit in addition to the insurance premium. In conclusion, insurance increases producers' demand for credit and increases it much more when both contracts are linked or bundled.

The superiority of the bundle (index insurance + agricultural credit) on separated contracts (credit only or insurance only) was also highlighted by De Nicola (2015). The richest households purchase index insurance more than poor households to the point at which they manage to insure their own assets. This result matches that of Clarke (2016) according to which insurance demand is a parabolic function of wealth. For De Nicola (2015) and De Nicola and Hill (2013), access to credit gives the producer a certain level of wealth which makes him to demand an insurance cover because the gain in terms of welfare provided by an insured credit is greater than the gain from the single index insurance contract (not linked to credit). These authors also found that this gain in terms of well-being is more important for poor producers who decide to buy a credit-related contract.

Elabed et al. (2013) also studied the demand for index insurance in relation to access to credit. They found that index insurance could remove constraints on access to agricultural finance by unlocking access to credit for producers. 


\section{Modeling the Demand of Micro-Insurance Bundled with Agricultural Credit}

We propose here a model of demand for index-based insurance linked to agricultural loan. Our objective is to theoretically analyse the relationship between index-based insurance demand and agricultural loan to understand the conditions under which the later could stimulate insurance demand. The details of the model will be presented firstly before discussing its results secondly.

In order to do so, we start from two previous works on the demand for agricultural insurance by small farmers in developing countries. It is primarily about Sarris (2002) who proposed a theoretical model for determining demand for insurance against cocoa price fluctuations in Ghana and secondly from Carter et al. (2014) work that analyzed the determinants of index-based insurance demand. Indeed the work of Carter et al. (2014) is somehow an adaptation of the work of Sarris (2002) to the demand of index-based insurance.

As a starting point, it is assumed that each year the agricultural activities are carried out over a finite time horizon called the agricultural season which is divided into two periods. The first period is that of production. The period of production starts just before the first rainfall (one to two months before) and goes till the end of the rainy period. The risk thus weighs on this period which starts at the moment of the preparation of the season. During that moment the producer register at the same time for the credit and the insurance products. That first period ends at the time of the harvests. The second period is the period of sale or marketing of the harvest. During this period, the farming activity normally begins to generate incomes which will then be used to repay the credit if there has been no loss and the index-based insurance has not triggered compensation.

We start with the consumption model of Carter et al. (2014) and Sarris (2002): $c\left(y_{t}\right)=c_{t}^{*}+\beta\left(y_{t}-y_{t}^{*}\right)$. In the model, $y_{t}$ is the current income. It is exogenous and random. $y_{t}^{*}$ is the permanent income with $c_{t}^{*}$ the corresponded permanent consumption. $\beta$ is the factor of consumption smoothing. In that model, the consumption depends on the variation of the current income around the permanent income and the parameter of smoothing $\beta$. If $\beta=0$, the smoothing is perfect and the current consumption is independent from the current income. If $\beta=0$ there is no smoothing at all and the current consumption varies in the same way than the current income through for example the sales of the assets when a shock occurs.

Considering that model, we suppose the income that enable the consumption comes from the use of agricultural credit, $a$. The agricultural credit (a) is provided to the farmer for its production and it is invested at the beginning of the agricultural season during the first period. The credit invested will then provide after its reimbursement a supplement income $\left(r_{t}-i_{t}\right) a_{t}$ with $\left(r_{t}-i_{t}\right)$ representing the benefit of the agricultural credit, $r_{t}$ the return rate of the agricul- 
tural credit and $i_{t}$ its interest rate. That supplement income $\left(\left(r_{t}-i_{t}\right) a_{t}\right)$ will be used to cover the expenses of consumption during the period 2 of the current agricultural season (period of marketing of the harvest), but also during the production period of the next agricultural season. In another way, for each agricultural season, the income that enables the consumption of the current period depends on the profits from the investment made with credit of the previous period $\left((r-i) a_{t-1}\right)$. The benefits of the credit enable then the consumption during the period of marketing of the current production and during the next period of production (that of the next agricultural season).

To introduce the credit, we replace in the consumption model given by $c\left(y_{t}\right)=c_{t}^{*}+\beta\left(y_{t}-y_{t}^{*}\right)$, the expression $\beta\left(y_{t}-y_{t}^{*}\right)$ by the expression $\left(\left(r_{t-1}-i_{t-1}\right) a_{t-1}\right)$ and we call $\left(r_{t-1}-i_{t-1}\right)$ the benefit of the agricultural credit at $t-1, r_{t-1}$ is the return rate of the agricultural credit and $i_{t-1}$ is its interest rate. We can then rewrite the consumption model as follow:

$$
c\left(a_{t-1}\right)=c_{t}^{*}+\left(r_{t-1}-i_{t-1}\right) a_{t-1}
$$

Figure 1 shows how the credit participates in the consumption during the two periods that define the agricultural season: the period of production and the period of marketing.

To analyse the demand for index insurance when the producer has access to agricultural credit as described in this context, we proceed in two steps:

First we consider a model in which 1) the producer is not required to provide a collateral to access agricultural credit, the idea being that agricultural insurance will be considered a substitute for the collateral and the producers who, at the time of their loan application, decide to purchase the insurance will not need to pledge their assets; 2) the insurance premium is not pre-financed by the agricultural credit and is therefore not subject to the interest rate. For example, the premium can be paid directly by the producer or pre-financed by another non-financial institution to which the producer is affiliated such as a farmer organization (cooperative, savings group, etc.).

Then, we will complete the simple model by considering the case where 1) a collateral is asked to the producer to access agricultural credit, whether he has subscribed or not to index-based insurance. In fact, the presence of the basis risk and the lack of coverage of idiosyncratic risks by index insurance justify the request for a collateral by the credit institution. 2) The insurance premium will be pre-financed by agricultural credit to compensate for liquidity constraints that may block the payment of the premium. As a result, the latter will be hit by the interest rate that applies to the agricultural credit.

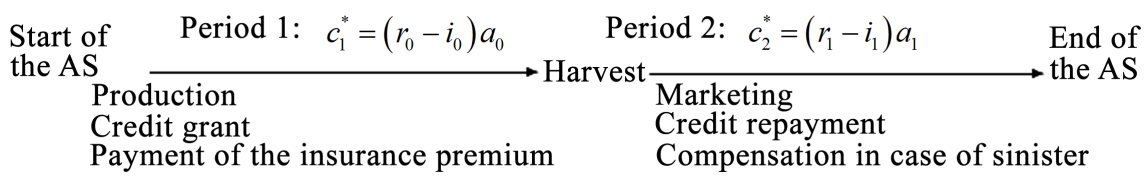

Figure 1. Description of the activities during the agricultural season. Source: Author. 


\subsection{The Simple Model}

There are different factors in the definition of the utility function based on whether the producer has bought the insurance or not and whether we are on the first or the second period of the agricultural season. Without the insurance contract, the associated utility of the first period of the season (period of production) is $U\left(c\left(a_{0}\right)\right)$ since it depends on the return on investment of the previous credit $\left(a_{0}\right)$. For the utility of the second period, it is uncertain because it depends on the variability of the rains which occur during the first period. It is hence given by $E U\left(c\left(a_{1}\right)\right)$. With the insurance contract, the utility of the first period becomes $U\left(c\left(a_{0}-B\right)\right)$ and that of the second period $E U\left(c\left(a_{1}+z\right)\right)$ with $B$ the premium paid and $z$ the indemnification. The index 0 and 1 refer to the different periods of the agricultural season, namely the period of production at $t=0$ and the period of marketing at $t=1$.

Table 1 provides the utility functions of the farmers for each of the agricultural season depending on whether they are insured or not in a context of bundling with micro-credit. If the revenue from the agricultural production are above the amount of credit invested increased by its cost, the agricultural loan is hence profitable to the producer $\left(\left(r_{t}-i_{t}\right) a_{t}>0\right)$. We also suppose in addition that the agricultural credit is used only for the production and not for consumption. In fact, the producer gets the credit at the beginning of the agricultural season and reimburses it during the marketing period of the same season. It is the profit he gets after repayment $\left(\left(r_{t}-i_{t}\right) a_{t}\right)$ which interests us here because it is this one which allows the smoothing of the consumption of the later periods.

\subsubsection{Condition of Uptake of the Insurance}

In order for the producer to agree to pay for the insurance product, it must allow him to keep at least the same level of utility as if he did not subscribe to it. In other words, the insured agricultural season should provide to the farmer the same level of utility than the agricultural season for which he has not purchase the insurance. For this, the premium $(B)$ must be equal to the producer's willingness to pay. The latter is in turn regarded as the profit from the insurance contract since it is the part that must be deducted from the income of the first period of the agricultural season so that the utility of the entire season with the insurance is equal to its utility without the insurance. Hence, with the same level

Table 1. Possible utility functions in the case of the simple model.

\begin{tabular}{ccc}
\hline & Without insurance & With insurance \\
\hline $\begin{array}{cc}\text { Period } \\
1\end{array}$ & $U\left(c_{1}^{*}+a_{0}\left(r_{0}-i_{0}\right)\right)$ & $U\left(c_{1}^{*}+a_{0}\left(r_{0}-i_{0}\right)-B\right)$ \\
$\begin{array}{c}\text { Period } \\
2\end{array}$ & $E U\left(c_{2}^{*}+a_{1}\left(r_{1}-i_{1}\right)\right)$ & $E U\left(c_{2}^{*}+a_{1}\left(r_{1}-i_{1}\right)+z\right)$ \\
AS & $U\left(c_{1}^{*}+a_{0}\left(r_{0}-i_{0}\right)\right)+\delta E U\left(c_{2}^{*}+a_{1}\left(r_{1}-i_{1}\right)\right)$ & $U\left(c_{1}^{*}+a_{0}\left(r_{0}-i_{0}\right)-B\right)+\delta E U\left(c_{2}^{*}+a_{1}\left(r_{1}-i_{1}\right)+z\right)$ \\
\hline
\end{tabular}

AS $=$ Agricultural Season $=$ Period $1+$ Period 2. Source: Author. 
of utility, the willingness to pay allows the producer to transfer the risk that weighs on the second period to his insurer.

In each case, with or without insurance of the agricultural season, we have a discrete intertemporal utility function with uncertainty intervening in the second period. $\delta$ represents the individual discount factor (or discount rate). The producer will then choose the amount of $B$ that will allow him to equalize the utility derived from the crop year in both cases:

$$
\begin{aligned}
& U\left(c_{1}^{*}+a_{0}\left(r_{0}-i_{0}\right)\right)+\delta E U\left(c_{2}^{*}+a_{1}\left(r_{1}-i_{1}\right)\right) \\
& =U\left(c_{1}^{*}+a_{0}\left(r_{0}-i_{0}\right)-B\right)+\delta E U\left(c_{2}^{*}+a_{1}\left(r_{1}-i_{1}\right)+z\right)
\end{aligned}
$$

At this point, we can rewrite this equality using Taylor's expansions of each of its terms.

For the left terms, we will have:

- $U\left(c_{1}^{*}+a_{0}\left(r_{0}-i_{0}\right)\right)=U^{*}+a_{0}\left(r_{0}-i_{0}\right) U^{\prime *}+\frac{1}{2} a_{0}^{2}\left(r_{0}-i_{0}\right)^{2} U^{\prime \prime *}$

- $E U\left(c_{2}^{*}+a_{1}\left(r_{1}-i_{1}\right)\right)=E U^{*}+a_{1}\left(r_{1}-i_{1}\right) E U^{\prime *}+\frac{1}{2} a_{1}^{2}\left(r_{1}-i_{1}\right)^{2} E U^{\prime *}$

Similarly, we will have for the terms on the right:

$$
\begin{aligned}
& \text { - } U\left(c_{1}^{*}+a_{0}\left(r_{0}-i_{0}\right)-B\right)=U^{*}+\left(a_{0}\left(r_{0}-i_{0}\right)-B\right) U^{\prime *}+\frac{1}{2}\left(a_{0}\left(r_{0}-i_{0}\right)-B\right)^{2} U^{\prime *} \\
& E U\left(c_{2}^{*}+a_{1}\left(r_{1}-i_{1}\right)+z\right) \\
& =E U^{*}+\left(a_{1}\left(r_{1}-i_{1}\right)+z\right) E U^{\prime *}+\frac{1}{2}\left(a_{1}\left(r_{1}-i_{1}\right)+z\right)^{2} E U^{\prime \prime *}
\end{aligned}
$$

By replacing the expressions of the Taylor expansions of each term in Equation (2), we obtain after simplifications the following Equation (3):

$$
B-\rho a_{0} B\left(r_{0}-i_{0}\right)+\frac{1}{2} \rho B^{2}-\delta E(z)+\delta \rho a_{1} E\left[z\left(r_{1}\right)-i_{1}\right]+\frac{1}{2} \delta \rho E\left(z^{2}\right)=0
$$

Equation (3) gives the value of $B$ that the producer must give up during the production period to ensure a level of utility equal to what he would have if he were not to insure during the entire agricultural season. We can already notice a result without novelty: if the coefficient of risk aversion is zero $(\rho=0)$, then $B=\delta E z$. On the other hand, if the credit is not profitable and does not allow the smoothing of consumption $\left(\left(r_{0}-i_{0}\right)=0 \&\left(r_{1}-i_{1}\right)=0\right)$ then we have the following expression: $B=\frac{1}{2} \rho B^{2}-\delta E z+\frac{1}{2} \delta \rho E z^{2} . B$ will then increase with the discount rate $(\delta)$ and the value of the expected pay-out $(E z)$.

Considering now the Equation (2), we are interested in the relationship between the demand of insurance $(B)$ and the profitability of the agricultural credit $(r-i)$. Therefore, we perform the differentiation of Equation (3) with respect to $(r-i)$, assuming that $\left(r_{0}-i_{0}\right)=\left(r_{1}-i_{1}\right)=(r-i)$. We obtain the expression of Equation (4):

$$
\frac{\partial B}{\partial(r-i)}=\rho\left(\delta E z a_{1}-B a_{0}\right)
$$


First we discuss the cases where the credit of the production period of the previous agricultural season is equal to that of the production period of the current agricultural season $\left(a_{0}=a_{1}\right)$, then the case where the credits of the two production periods are different $\left(a_{0} \neq a_{1}\right)$.

- Case 1: $a_{0}=a_{1}: \frac{\partial B}{\partial(r-i)}=\rho a_{1}(\delta E z-B)$

Therefore, if the insurance premium is not pre-financed, a collateral is not requested as a condition of access to the credit and the producer has an amount of credit for the current crop year $\left(a_{1}\right)$ equal to the amount received during the previous agricultural season $a_{0}$, then the benefit of $B$ insurance increases with the benefit of the credit $(r-i)$ if $\delta E z \geq B$. In other words, the more the credit is profitable, the more the farmers will be willing to pay for the insurance.

- Case 2: $a_{0} \neq a_{1}: \frac{\partial B}{\partial(r-i)}=\rho\left(\delta E z a_{1}-B a_{0}\right)$

However, in the case where the insurance premium is not pre-financed, a collateral is not requested as a condition of access to the credit but the credit amounts of the two production periods are different $\left(a_{0} \neq a_{1}\right)$, if the benefit of the credit $(r-i)$ increases the benefit of the insurance $(B)$ increases only if $\delta E z a_{1} \geq B a_{0}$. We conclude that, the benefit (willingness to pay) of the insurance increases with the benefit of the credit only if the producer increases the amount of the credit which he uses from one crop year to another.

\subsubsection{The Optimal Demand in the Case of the Simple Model}

In fact, the equalization of the utility functions of the insured agricultural season and the uninsured agricultural season in Equation (2) gives just the amount of the willingness to pay that allows the producer to start benefiting from the agricultural insurance. The producer must seek to maximize this benefit and to do so, he must maximize the difference between these two utility functions. However, since this maximization is performed by choosing the optimal value of $B$, maximizing the difference between the two amounts returns to maximizing only the utility of the insured agricultural season:

$$
\operatorname{Max}(B): U=U\left(c_{1}^{*}+a_{0}\left(r_{0}-i_{0}\right)-B\right)+\delta E U\left(c_{2}^{*}+a_{1}\left(r_{1}-i_{1}\right)+z\right)
$$

The optimal value of the premium that will allow the producer to maximize the utility he obtains from the agricultural season when he decides to purchase the insurance is then:

$$
B^{*}=a_{0}\left(r_{0}-i_{0}\right)-\frac{1}{\rho} B
$$

We conclude that in the absence of a request for a collateral to access the loan and an absence of a pre-financing of the insurance premium by the credit, the optimal amount that the producer is willing to pay $\left(B^{*}\right)$ is an increasing function of the benefit of the credit (its profitability) he has received during the previous crop year $a_{0}(r-i)$ and an increasing function of the level of risk aver- 
sion $\rho$. The purchase of the insurance policy will occur if the optimal value of the producer's willingness to pay $\left(B^{*}\right)$ is greater than the premium majored by the the insurer's charges $(m)$.

$$
\text { take-up }=\left\{\begin{array}{l}
1, \text { if } B^{*} \geq \text { premium }=\operatorname{cost} \times(1+m) \\
0, \text { if not }
\end{array}\right.
$$

\subsection{The Complete Model}

Now we include the collateral $(g)$ as a condition of access to the credit and also the possibility to pre-finance the insurance premium by the credit itself, which increases it by $(i B)$. The collateral can be in monetary or material form but in all cases it must be provided at the time of the application for credit, namely at the beginning of the production period. It is then fully returned to the producer if he repays the credit during the marketing period. Without the insurance contract, the utility associated with the consumption of the first period is $U\left(c_{1}\left(a_{0}-g\right)\right)$ and that of the second period $E U\left(c_{2}\left(a_{1}+g\right)\right)$. With the insurance contract, the utility of the first period becomes $U\left(c_{1}\left(a_{0}-(g+(1+i) B)\right)\right)$ and that of the second period will be $E U\left(c_{2}\left(a_{1}+(g+z)\right)\right)$.

Table 2 presents the expansive forms of the utility functions of the complete model. In that model, the producer must provide a collateral at the time he applies for credit and must also pay interests on the insurance premium which is deducted directly from the amount of the credit he is granted. The utility functions are given according to the periods and whether the producer purchases the insurance or not. We also, assume that we are in a context of availability of the credit, which is the only source of funding the farmers have access to make an agricultural investment.

\subsubsection{Condition of Uptake of the Insurance}

As in the simple model, for the producer to subscribe to the agricultural insurance it should allow him at least to reach the same level of utility as in the case in which he is not insured. Hence $B$ will always represent the amount that must be withdrawn from the production period to equalize the utility obtained from the insured agricultural season to that of the uninsured agricultural season. $B$ is then the willingness to pay which is also interpreted as the benefit from the insurance contract. The condition of subscription to the insurance is then the following one:

Table 2. Description on the utility function in case of the complete model.

\begin{tabular}{ccc}
\hline & Without insurance & With insurance \\
\hline Period 1 & $U\left(c_{1}^{*}+a_{0}\left(r_{0}-i_{0}\right)-g\right)$ & $U\left(c_{1}^{*}+a_{0}\left(r_{0}-i_{0}\right)-B\right)$ \\
Period 2 & $E U\left(c_{2}^{*}+a_{1}\left(r_{1}-i_{1}\right)+g\right)$ & $E U\left(c_{2}^{*}+a_{1}\left(r_{1}-i_{1}\right)+z\right)$ \\
AS & $U\left(c\left(a_{0}-g\right)\right)+\delta E U\left(c\left(a_{1}+g\right)\right)$ & $U\left(c\left(a_{0}-\left(g+\left(1+i_{0}\right) B\right)\right)\right)+\delta E U\left(a_{1}+(g+z)\right)$ \\
\hline
\end{tabular}

AS $=$ Agricultural Season $=$ Period 1 (production $)+$ Period $2($ Marketing $)$. 


$$
\begin{aligned}
& U\left(c_{1}^{*}+a_{0}\left(r_{0}-i_{0}\right)-g\right)+\delta E U\left(c_{2}^{*}+a_{1}\left(r_{1}-i_{1}\right)+g\right) \\
& =U\left(c_{1}^{*}+a_{0}\left(r_{0}-i_{0}\right)-(g+i B)\right)+\delta E U\left(c_{2}^{*}+a_{1}\left(r_{1}-i_{1}\right)+(g+z)\right)
\end{aligned}
$$

By introducing Taylor's expansions, equality 6 can be presented in this way:

$$
\begin{aligned}
& \left(1+i_{0}\right) B-a_{0} \rho B\left(r_{0}-i_{0}\right)\left(1+i_{0}\right)+\left(1+i_{0}\right) g B \rho+\frac{1}{2} B^{2}\left(1+i_{0}\right)^{2} \rho-\delta E(z) \\
& +\left(E\left(r_{1}\right)-i_{1}\right) \delta E(z) a_{1} \rho+\frac{1}{2} \delta E\left(z^{2}\right) \rho+\delta g E(z) \rho=0
\end{aligned}
$$

We can also note that in the absence of risk aversion $(\rho=0),\left(1+i_{0}\right) B=\delta E z$ and $B=\left(1-i_{0}\right) \delta E z$.

To get the relationship between the insurance benefit $(B)$ and the profitability of the agricultural credit $(r-i)$, we differentiate Equation (7), assuming that $\left(r_{0}-i_{0}\right)=\left(r_{1}-i_{1}\right)=(r-i)$. We get the expression of Equation $(8)$ :

$$
\frac{\partial B}{\partial(r-i)}=\rho\left(\delta E z a_{1}-B a_{0}\left(1+i_{0}\right)\right)
$$

We discuss now the case where the amount of credit that is necessary for the consumption smoothing through its return on investment is the same from one agricultural season to another firstly. The case where the credit of the current agricultural season is different from that of the previous agricultural season is discussed secondly.

- Case 1: $a_{0}=a_{1}: \frac{\partial B}{\partial(r-i)}=\rho\left(\delta E z a_{1}-B a_{0}(1+i)\right)$

With an interest rate that applies on the insurance premium and also with a collateral as a condition of access to the credit, the willingness to pay of the producer increases with $(r-i)$ only if the premium is actuarially favourable $\geq B(1+i)$. But with the interest rate on the premium, the willingness to pay increases less than proportionally as the benefit from credit increases.

- Case 2: $a_{0} \neq a_{1}: \frac{\partial B}{\partial(r-i)}=\rho\left(\delta E z a_{1}-B a_{0}(1+i)\right)$

This result indicates that if the benefit from the agricultural investment made with the credit $(r-i)$ increases, the benefit of the insurance, $B$, increases only if $\delta a_{1} E z \geq a_{0} B(1+i)$. With an actuarially fair premium $(\delta E z=B(1+i))$ for example, this result shows that if the producers increase the level of their investment between crop years, then the willingness to pay increases with the profitability of the agricultural credit.

\subsubsection{The Optimal Demand in the Case of the Complete Model}

The optimal amount that the producer will spend on the insurance premium is obtained by maximizing the expected utility of the insured agricultural season.

$$
\begin{aligned}
\operatorname{Max}(B): U= & U\left(c_{1}^{*}+a_{0}\left(r_{0}-i_{0}\right)-(g+(1+i) B)\right) \\
& +\delta E U\left(c_{2}^{*}+a_{1}\left(r_{1}-i_{1}\right)+(g+z)\right)
\end{aligned}
$$

The expression of the optimal value of $B$ will be given by: 


$$
B^{*}=\frac{a_{0}\left(r_{0}-i_{0}\right)-g}{1+i_{0}}-\frac{1}{\rho\left(1+i_{0}\right)}
$$

The optimal amount that the producer will be willing to pay for the insurance during the current agricultural season is an increasing function of the return on investment of the previous agricultural season $\left(a_{0}\left(r_{0}-i_{0}\right)\right)$, a decreasing function of the amount of collateral and an increasing function of the level of risk aversion $(\rho)$. As in the simple model, here also the underwriting of the insurance policy will take place if the producer's optimal willingness to pay $B^{*}$ is larger than the premium majored by the insurer's charges $(m)$.

$$
\text { take-up }=\left\{\begin{array}{l}
1, \text { if } B^{*} \geq \text { premium }=\operatorname{cost} \times(1+m) \\
0, \text { if not }
\end{array}\right.
$$

\section{Discussion}

Through the linkage between crop index-based insurance and agricultural credit, producers in some developing countries such as Senegalese farmers are given the option of deferring payment of premiums until repayment of the loan, which improves access to the insurance product. Access to credit thus has a positive effect on the demand for insurance. Similarly, for credit applicants who decide to insure, the amount that is required as a collateral can be lowered because insurance is also considered a form of collateral that protects the lender against payment default. This is supposed to improve access to credit for the poorest farmers who do not have enough collateral to propose to micro-finance institutions and could then be considered as a positive effect of insurance on the demand for credit and on agricultural investment. A complementary relationship is thus established between crop index-based insurance and agricultural credit through the fact that they mutually improve their demand.

The theoretical verification of this positive relationship between insurance and credit when they are linked through the model developed in this chapter has shown that demand for insurance increases with the increase of the profitability of agricultural credit. For that profitability to increase, it is necessary for its cost (the interest rate) to be lower than its return rate so that the producer can be interested in the insurance after each agricultural season. With regard to collateral, producers would expect their uptake of crop index-based insurance to allow their lender to reduce the level of collateral they request on each application to an agricultural credit. The model shows that the lower the amount of the collateral on the credit requested, the higher the benefit of the insurance and the chances of purchasing it.

Connected to the theoretical literature, our results are in line with those of (Dercon et al., 2019), who emphasized the fact that linking insurance with credit was more beneficial than offering insurance in a separate contract. Their results also showed that the contracts that bundles insurance and agricultural credit attract more poor farmers who are excluded from the financial system and who do 
not have a formal separated insurance contract at the time of their application to agricultural credit. This is consistent with our finding that demand for agricultural insurance is higher among producers with low level of collateral. Similarly, with respect to the interest rate, (Dercon et al., 2019) show that, in the absence of crop index-based insurance, interest rates on credit increase with the decreasing of the level of collateral presented by the credit applicants. They continue their analysis by showing that with index-based insurance linked to credit, lenders no longer feel the need to raise interest rates even when the value of the collateral are low. This result is also in line with our result which states that demand for crop insurance is an increasing function of the profitability of the credit, hence a decreasing function of its interest rate.

Several crop index-based micro-insurance pilots in developing countries aimed to get farmers to abandon low-risk low-return investment strategies to adopt farming techniques that require more resources but are more profitable (Karlan et al., 2012). This objective could be achieved if farmers feel more confident and are hence more willing to invest more because they benefit from an insurance contract that transfers part of the risk of default on loans to insurers. In addition, index-based insurance would allow lenders to overcome the systemic risks they face when they have a large number of credits exposed to agricultural risks in their portfolios. Another advantage of linking micro-insurance contracts with agricultural credit is the possibility it offers the lender (or any other intermediary who has to manage the risks that his members or clients transfer to him) to worry less about collateral because the insurance can be a form of loan security.

\section{Conclusion}

A major problem of agricultural activities in developing countries is the reluctance of poor rural households to adopt new production techniques. Liquidity constraints due to low access to credit have been cited as one of the main reasons why farmers adopt low-risk investment strategies for low returns (Duflo et al., 2004; Feder and Umali, 1993). To deal with that issue the distribution patterns of (index) micro-insurance are changing in most of the developing countries, particularly in West Africa. For example, in Senegal, the National Agricultural Insurance Company (CNAAS) relies on farmers' organizations, which serve as intermediaries to reach small farmers. The objective of our work was to analyse the demand for micro-insurance when it is linked to agricultural credit as is the case in Senegal, through a theoretical model. The exercise consisted of putting in relationship the demand for crop index-based insurance with the characteristics of agricultural credit, such as the interest rate and the level of collateral requested.

A first simple model in which a collateral is not requested and where the producer pays the insurance premium before the credit is granted was first presented. It is then completed by 1 ) integrating the collateral as a necessary condition to access the loan and by 2) taking into account the possibility of including 
the amount of the insurance premium in the amount of the agricultural credit demanded thus allowing to postpone its settlement until the repayment of the agricultural loan. In Senegal, it is this model of offer that is developing since the introduction of crop index-based insurance in 2012. Producers who are members of farmers' organizations or clients of micro-finance institution who provide agricultural loans, either in the form of cash or in the form of inputs (equipment, fertilizers, seeds), have the possibility to purchase a crop index-based insurance which enables them to cover the credit contracted during the agricultural season against climate risks such as rainfall variability (Syll and Weingaertner, 2018).

Our results show a positive relationship between the demand for crop index-based insurance and agricultural credit through the return on investment (or profitability) of the latter during the previous agricultural season and the amount of collateral requested from the farmer during the starting agricultural season. In other words, a good agricultural season obtained today thanks to agriculture credit would increase the demand for insurance during the next season. However, the amount of collateral requested when granting loans lead to a decrease in demand for crop insurance when linked to agricultural credit.

However, as theoretical results do not systematically coincide with empirical results, which can be much more complex, the following questions must be answered empirically to confirm our conclusions. In practice, does bundling micro-insurance to agricultural credit lead to more agricultural investment by the farmers? Do more farmers get insured in that case? What about a decreasing in collateral and interest rate on the credit? Does it also lead to more insurance take-up?

\section{Conflicts of Interest}

The author declares no conflicts of interest regarding the publication of this paper.

\section{References}

Carter, M. R., Cheng, L., \& Sarris, A. (2011). The Impact of Interlinked Index Insurance and Credit Contracts on Financial Market Deepening and Small Farm Productivity. Annual Meeting of the American Applied Economics Association, Pittsburgh, July 2011, 24-26.

Carter, M., de Janvry, A., Sadoulet, E., \& Sarris, A. (2014). Index-Based Weather Insurance for Developing Countries: A Review of Evidence and a Set of Propositions for Up-Scaling. Development Policies Working Paper 111.

Clarke, D. J. (2016). The Rational Demand for Index Insurance. American Economic Journal: Microeconomics, 1, 283-306. https://doi.org/10.1257/mic.20140103

Cole, S., Gine, X., Tobacman, J., Topalova, P., Townsend, R., \& James, V. (2013). Barriers to Household Risk Management: Evidence from India. American Economic Journal: Applied Economics, 5, 104-135. https://doi.org/10.1257/app.5.1.104

Collier, B., Skees, J., \& Barnett, B. (2009). Weather Index Insurance and Climate Change: 
Opportunities and Challenges in Lower Income Countries. The Geneva Association Papers, 34, 401-424. https://doi.org/10.1057/gpp.2009.11

De Nicola, F. (2015). Handling the Weather: Insurance, Savings and Credit in West Africa. Technical Report, World Bank Policy Research Working Paper No. 7187. https://doi.org/10.1596/1813-9450-7187

De Nicola, F., \& Hill, R. V. (2013). Interplay among Credit, Weather Insurance and Savings for Farmers in Ethiopia. Presentation at the American Economic Association Meeting, San Diego, 4-6 January 2013.

Dercon, S., Gunning, J. W., \& Zeitlin, A. (2019). The Demand for Insurance under Limited Credibility: Evidence from a Field Experiment in Kenya. CSAE Working Paper Series 2019-06, Centre for the Study of African Economies, University of Oxford. https://ideas.repec.org/p/csa/wpaper/2019-06.html

Doherty and Shlesinger (1990). Rational Insurance Purchasing: Consideration of a Contract Non-Performance. The Quarterly Journal of Economics, 1, 243-253. https://doi.org/10.2307/2937829

Duflo, E., Kremer, M., \& Robinson, J. (2004). Understanding Technology Adoption: Fertilizer in Western Kenya Preliminary Results from Field Experiments. Unpublished Manuscript, Massachusetts Institute of Technology.

Elabed, G., Bellemare, M. F., \& Carter, M. R. (2013). Managing Basis Risk with Multiscale Index Insurance. Agricultural Economics, 44, 419-431.

https://doi.org/10.1111/agec.12025

Eling, M., Pradhan, S., \& Shmit, J. T. (2014). The Determinant of Microinsurance Demand. The Geneva Papers on Risk and Insurance-Issues and Practice, 39, 224-263. https://doi.org/10.1057/gpp.2014.5

Feder, G., \& Umali, D. L. (1993). The Adoption of Agricultural Innovations: A Review. Technological Forecasting and Social Change, 43, 215-239. https://doi.org/10.1016/0040-1625(93)90053-A

Giné, X., \& Yang, D. (2008). Patterns of Rainfall Insurance Participation in Rural India. The World Bank Economic Review, 22, 539-566. https://doi.org/10.1093/wber/lhn015

Giné, X., \& Yang, D. (2009). Insurance Credit and Technology Adoption: Field Experimental Evidence from Malawi. Journal of Development Economics, 89, 1-11. https://doi.org/10.1016/j.jdeveco.2008.09.007

Gollier, C. (2003). To Insure or Not to Insure? An Insurance Puzzle. Geneva Paper on Risk and Insurance Theory, 68, 1-24. https://doi.org/10.1023/A:1022112430242

Hazel, P., Erson, J., Balzer, N. C. H., Hess, U., \& Rispoli, F. (2010). Potential for Scale and Sustainability in Weather Index Insurance for Agriculture and Rural Livelihoods. Technical Report, International Fund for Agricultural Development and World Food Program.

Hill, Ruth, V., \& Robles, M. (2011). Flexible Insurance for Heterogenous Farmers : Results from a Small Scale Pilot in Ethiopia. Discussion Papers.

Jensen, N. D., Mude, A., \& Barrett, C. B. (2014). How Basis Risk and Spatiotemporal Adverse Selection Influence Demand for Index Insurance: Evidence from Northern Kenya. https://doi.org/10.2139/ssrn.2475187

Karlan, D., Osei, R. D., Osei-Akoto, I., \& Udry, C. (2012). Agricultural Decisions after Relaxing Credit and Risk Constraints. Technical Report, National Bureau of Economic Research. https://doi.org/10.3386/w18463

Liu, Y., \& Myers, R. J. (2012). The Dynamics of Insurance Demand under Liquidity Con- 
straints and Insurer Default Risk. Discussion Paper 01174, IFPRI.

Marr, A., Winkel, A., Asseldonk, M. V., Lensink, R., \& Bulte, E. (2016). Adoption and Impact of Index-Insurance and Credit for Smallholder Farmers in Developing Countries: A Systematic Review. Agricultural Finance Review, 76, 94-118.

https://doi.org/10.1108/AFR-11-2015-0050

Matul, M., Dalal, A., De Bock, O., \& Gelade, W. (2013). Why People Do Not Buy Microinsurance and What We Can Do about It? Technical Report, International Labour Organization.

Mossin, J. (1968). Aspects of Rational Insurance Purchasing. The Journal of Political Economy, 4, 553-568. https://doi.org/10.1086/259427

Roberts, R. A. J. (2005). Insurance of Crops in Developing Countries. Technical Report, FAO Agricultural Services, Bulletin Number 159.

Sarris, A. H. (2002). The Demand for Commodity Insurance by Developing Country Agricultural Producers: Theory and an Application to Cocoa in Ghana. World Bank Policy Research Working Paper, Number 2887. https://doi.org/10.1596/1813-9450-2887

Syll, M. M., \& Weingaertner, L. (2018). Disposition à payer pour l'assurance agricole basée sur les indices climatiques au sénégal. Revue Française d'Economie, 32, 18-45. https://doi.org/10.3917/rfe.173.0018

Takahashi, K., Ikegami, M., Sheahan, M., \& Barrett, C. B. (2016). Experimental Evidence on the Drivers of Index-Based Livestock Insurance Demand in Southern Ethiopia. World Development, 78, 324-340. https://doi.org/10.1016/j.worlddev.2015.10.039

The World-Bank (2009). Index-Based Crop Insurance in Senegal: Promoting Access to Agricultural Insurance for Small Farmers. The World-Bank, Sustainable Development, Africa Region, Finance and Private Sector Development.

Zimmerman, E., Bauchet, J., Magnoni, B., \& Larsen, V. (2016). Responsible Bundling of Microfinance Services: A Mixed Method Evaluation of the Impact of Timing, Pressure and Information. Working Paper. 


\section{Appendix: Proof of Results}

\section{1) Simple model: proof of result (3)}

We recall that the condition for the purchase of the insurance by a farmer in this model is given by:

$$
\begin{aligned}
& U\left(c_{1}^{*}+a_{0}(r-i)\right)+\delta E U\left(c_{2}^{*}+a_{1}(r-i)\right) \\
& =U\left(c_{1}^{*}+a_{0}(r-i)-B\right)+\delta E U\left(c_{2}^{*}+a_{1}(r-i)+z\right)
\end{aligned}
$$

The expansion of Taylor on each of its terms provide:

For the left terms we will have:

- $U\left(c_{1}^{*}+a_{0}\left(r_{0}-i_{0}\right)\right)=U^{*}+a_{0}\left(r_{0}-i_{0}\right) U^{\prime *}+\frac{1}{2} a_{0}^{2}\left(r_{0}-i_{0}\right)^{2} U^{\prime \prime *}$

- $E U\left(c_{2}^{*}+a_{1}\left(r_{1}-i_{1}\right)\right)=E U^{*}+a_{1}\left(r_{1}-i_{1}\right) E U^{\prime *}+\frac{1}{2} a_{1}^{2}\left(r_{1}-i_{1}\right)^{2} E U^{\prime \prime *}$

Similarly, we will have for the terms on the right:

$$
\begin{aligned}
& U\left(c_{1}^{*}+a_{0}\left(r_{0}-i_{0}\right)-B\right) \\
& =U^{*}+\left(a_{0}\left(r_{0}-i_{0}\right)-B\right) U^{\prime *}+\frac{1}{2}\left(a_{0}\left(r_{0}-i_{0}\right)-B\right)^{2} U^{\prime \prime *} \\
& E U\left(c_{2}^{*}+a_{1}\left(r_{1}-i_{1}\right)+z\right) \\
& =E U^{*}+\left(a_{1}\left(r_{1}-i_{1}\right)+z\right) E U^{\prime *}+\frac{1}{2}\left(a_{1}\left(r_{1}-i_{1}\right)+z\right)^{2} E U^{\prime \prime *}
\end{aligned}
$$

After replacement of all the terms by their Taylor expansion, the relation (2) becomes:

$$
\begin{aligned}
& U^{*}+a_{0}(r-i) U^{\prime *}+\frac{1}{2} a_{0}^{2}(r-i)^{2} U^{\prime \prime *} \\
& +\delta\left(E U^{*}+a_{1}(r-i) E U^{\prime *}+\frac{1}{2} a_{1}^{2}(r-i)^{2} E U^{\prime \prime *}\right) \\
& =U^{*}+\left(a_{0}(r-i)-B\right) U^{\prime *}+\frac{1}{2}\left(a_{0}(r-i)-B\right)^{2} U^{\prime \prime *} \\
& +\delta\left(E U^{*}+\left(a_{1}(r-i)+z\right) E U^{\prime *}+\frac{1}{2}\left(a_{1}(r-i)+z\right)^{2} E U^{\prime *}\right) \\
& \Rightarrow U^{*}+a_{0} r_{0} U^{\prime *}-a_{0} i_{0} U^{\prime *}+\frac{1}{2}\left(a_{0}^{2} r_{0}^{2} U^{\prime *}-2 r_{0} i_{0} a_{0}^{2} U^{\prime *}+a_{0}^{2} i_{0}^{2} U^{\prime \prime *}\right) \\
& +\delta\left(E U^{*}+E a_{1} r_{1} U^{\prime *}-E a_{1} i_{1} U^{\prime *}+\frac{1}{2}\left(E a_{1}^{2} r_{1}^{2} U^{\prime \prime *}-2 E r_{1} i_{1} a_{1}^{2} U^{\prime \prime *}+E a_{1}^{2} i_{1}^{2} U^{\prime \prime *}\right)\right. \\
& =U^{*}+a_{0} r_{0} U^{\prime *}-a_{0} i_{0} U^{\prime *}-B U^{\prime *}+\frac{1}{2} a_{0}^{2} r_{0}^{2} U^{\prime \prime *}-2 r_{0} i_{0} a_{0}^{2} U^{\prime \prime *}+a_{0}^{2} i_{0}^{2} U^{\prime \prime *} \\
& -2 r_{0} B a_{0} U^{\prime \prime *}+2 i_{0} B a_{0} U^{\prime \prime *}+B^{2} U^{\prime \prime *}+\delta\left(E U^{*}+a_{1} E\left(r_{1} U^{\prime *}\right)-a_{1} i_{1} E\left(U^{\prime *}\right)\right. \\
& +E\left(z U^{\prime *}\right)+\frac{1}{2}\left(a_{1}^{2} E\left(r_{1}^{2} U^{\prime \prime *}\right)-2 i_{1} a_{1}^{2} E\left(r_{1} U^{\prime \prime *}\right)+a_{1}^{2} i_{1}^{2} E\left(U^{\prime \prime *}\right)\right. \\
& \left.\left.+2 a_{1} E\left(r_{1} z U^{\prime \prime *}\right)-2 i_{1} a_{1} E\left(z U^{\prime *}\right)+E\left(z^{2} U^{\prime \prime *}\right)\right)\right)
\end{aligned}
$$




$$
\begin{aligned}
& \Rightarrow U^{*}+a_{0} r_{0} U^{\prime *}-a_{0} i_{0} U^{\prime *}+\frac{1}{2}\left(a_{0}^{2} r_{0}^{2} U^{\prime *}-2 r_{0} i_{0} a_{0}^{2} U^{\prime *}+a_{0}^{2} i_{0}^{2} U^{\prime \prime *}\right)+\delta\left(E U^{*}\right. \\
& +a_{1} E\left(r_{1} U^{\prime *}\right)-a_{1} i_{1} E\left(U^{\prime *}\right)+\frac{1}{2}\left(a_{1}^{2} E\left(r_{1}^{2} U^{\prime \prime *}\right)-2 i_{1} a_{1}^{2} E\left(r_{1} U^{\prime \prime *}\right)+a_{1}^{2} i_{1}^{2} E\left(U^{\prime \prime *}\right)\right) \\
& =U^{*}+a_{0} r_{0} U^{\prime *}-a_{0} i_{0} U^{\prime *}-B U^{\prime *}+\frac{1}{2}\left(a_{0}^{2} r_{0}^{2} U^{\prime \prime *}-2 r_{0} i_{0} a_{0}^{2} U^{\prime \prime *}+a_{0}^{2} i_{0}^{2} U^{\prime \prime *}\right. \\
& \left.-2 r_{0} B a_{0} U^{\prime \prime *}+2 i_{0} B a_{0} U^{\prime \prime *}+B^{2} U^{\prime \prime *}\right)+\delta\left(E U^{*}+a_{1} E\left(r_{1} U^{\prime *}\right)-a_{1} i_{1} E\left(U^{\prime *}\right)\right. \\
& +E\left(z U^{\prime *}\right)+\frac{1}{2}\left(a_{1}^{2}\left(E r_{1}^{2} U^{\prime \prime *}\right)-2 i_{1} a_{1}^{2}\left(E r_{1} U^{\prime \prime *}\right)+a_{1}^{2} i_{1}^{2} E\left(U^{\prime \prime *}\right)\right. \\
& \left.+2 a_{1} E\left(r_{1} z U^{\prime \prime *}\right)-2 i_{1} a_{1} E\left(z U^{\prime \prime *}\right)+E\left(z^{2} U^{\prime \prime *}\right)\right)
\end{aligned}
$$

That yield the following reduced equation:

$$
\begin{aligned}
& -B U^{\prime *}-r_{0} B a_{0} U^{\prime \prime *}+i_{0} B a_{0} U^{\prime \prime *}+\frac{1}{2} B^{2} U^{\prime \prime *}+\delta E\left(z U^{\prime *}\right) \\
& +\delta a_{1} E\left(r_{1} z U^{\prime *}\right)-\delta i_{1} a_{1}\left(E z U^{\prime \prime *}\right)+\frac{1}{2} \delta E\left(z^{2} U^{\prime *}\right)=0
\end{aligned}
$$

Multiplying the expression by $\frac{-1}{U^{\prime *}}$, gives the following relation:

$$
\begin{aligned}
& -B \frac{-U^{\prime *}}{U^{\prime *}}-r_{0} B a_{0} \frac{-U^{\prime *}}{U^{\prime *}}+i_{0} B a_{0} \frac{-U^{\prime *}}{U^{\prime *}}+\frac{1}{2} B^{2} \frac{-U^{\prime *}}{U^{\prime *}}+\delta E\left(z \frac{-U^{\prime *}}{U^{\prime *}}\right) \\
& +\delta a_{1} E\left(r_{1} z \frac{-U^{\prime *}}{U^{\prime *}}\right)-\delta a_{1} i_{1} E\left(z \frac{-U^{\prime *}}{U^{\prime *}}\right)+\frac{1}{2} \delta E\left(z^{2} \frac{-U^{\prime \prime *}}{U^{\prime *}}\right)=0
\end{aligned}
$$

$\frac{-U^{\prime \prime *}}{U^{\prime *}}$ is the Arrow Pratt's risk aversion coefficient $(\rho)$. The expression becomes hence:

$$
\begin{aligned}
& B-r_{0} B a_{0} \rho+i_{0} B a_{0} \rho+\frac{1}{2} B^{2} \rho-\delta E(z)+\delta E(z) E\left(r_{1}\right) a_{1} \rho \\
& -\delta i_{1} E(z) a_{1} \rho+\frac{1}{2} \delta E\left(z^{2}\right) \rho=0
\end{aligned}
$$

Assuming that $E\left(z\left(r_{1}-i_{1}\right)\right)=E(z)\left(E\left(r_{1}\right)-i_{1}\right)$ and multiplying by $\left(r_{0}-i_{0}\right)$ and $\left(r_{1}-i_{1}\right)$ yield the expression below:

$$
B-\rho a_{0} B\left(r_{0}-i_{0}\right)+\frac{1}{2} \rho B^{2}-\delta E(z)+\delta \rho a_{1} E\left[z\left(r_{1}\right)-i_{1}\right]+\frac{1}{2} \delta \rho E\left(z^{2}\right)=0
$$

\section{2) Simple model: proof of result (4)}

We start from the condition of optimality given by the results (3) to draw the following relation:

$$
\begin{aligned}
& (E(r)-i)=f(B) \\
& \left.\left(E\left(r_{1}\right)-i_{1}\right)\right)=\frac{-B+\rho a_{0} B\left(r_{0}-i_{0}\right)-\frac{1}{2} \rho B^{2}+\delta E(z)-\frac{1}{2} \delta \rho E\left(z^{2}\right)}{\delta \rho a_{1} E(z)}
\end{aligned}
$$

To find the optimal value of $B$ that maximizes the benefit of the credit $\left.\left(E\left(r_{1}\right)-i_{1}\right)\right)$, we perform a partial differentiation. 


$$
\begin{aligned}
& \frac{\partial\left[\left(E\left(r_{1}\right)-i_{1}\right)\right]}{\partial B}=0 \rightarrow-1+\rho a_{0}\left(r_{0}-i_{0}\right)-\rho B=0 \rightarrow B=\frac{\rho a_{0}\left(r_{0}-i_{0}\right)-1}{\rho} \\
& \rightarrow B^{*}=a_{0}\left(r_{0}-i_{0}\right)-\frac{1}{\rho}
\end{aligned}
$$

\section{3) Complete model: proof of result (7)}

The condition of purchase of the insurance in the model complete is given by the following relation:

$$
\begin{aligned}
& U\left(c_{1}^{*}+a_{0}\left(r_{0}-i_{0}\right)-g\right)+\delta E U\left(c_{2}^{*}+a_{1}\left(r_{1}-i_{1}\right)+g\right) \\
& =U\left(c_{1}^{*}+a_{0}\left(r_{0}-i_{0}\right)-(g+B(1+i))+\delta E U\left(c_{2}^{*}+\left(a_{1}\left(r_{1}-i_{1}\right)+(g+z)\right)\right.\right.
\end{aligned}
$$

Taylor's expansion on each of the above terms gives:

For the first two terms of the relation:

$$
\begin{aligned}
& U\left(c_{1}^{*}+a_{0}\left(r_{0}-i_{0}\right)-g\right) \\
& =U^{*}+U^{\prime *}\left(a_{0}\left(r_{0}-i_{0}\right)-g\right)+\frac{1}{2} U^{\prime \prime *}\left(a_{0}^{2}\left(r_{0}-i_{0}\right)-g\right)^{2} \\
& E U\left(c_{2}^{*}+a_{1}\left(r_{1}-i_{1}\right)+g\right) \\
& =E U^{*}+E U^{\prime *}\left(a_{1}\left(r_{1}-i_{1}\right)+g\right)+\frac{1}{2} E U^{\prime \prime *}\left(a_{1}^{2}\left(r_{1}-i_{1}\right)+g\right)^{2}
\end{aligned}
$$

For the last two terms of the relation, we will have:

$$
\begin{aligned}
& U\left(c_{1}^{*}+a_{0}(r-i)-(g+B(1+i))\right) \\
& =U^{*}+U^{\prime *}\left(a_{0}(r-i)-(g+B(1+i))\right)+\frac{1}{2} U^{\prime \prime *}\left(a_{0}(r-i)-(g+B(1+i))\right)^{2} \\
& E U\left(c_{2}^{*}+\left(r_{1}-i_{1}\right)\left(a_{1}+(g+z)\right)\right. \\
& =E U^{*}+U^{\prime *}\left(a_{1}\left(r_{1}-i_{1}\right)+(g+z)\right)+\frac{1}{2} E U^{\prime \prime *}\left(a_{1}\left(r_{1}-i_{1}\right)+(g+z)\right)^{2}
\end{aligned}
$$

After replacing each term by its Taylor development, the relation becomes:

$$
\begin{aligned}
& U^{*}+U^{\prime *}\left(a_{0}\left(r_{0}-i_{0}\right)-g\right)+\frac{1}{2} U^{\prime \prime *}\left(a_{0}^{2}\left(r_{0}-i_{0}\right)-g\right)^{2} \\
& +\delta\left(E U^{*}+E U^{\prime *}\left(a_{1}\left(r_{1}-i_{1}\right)+g\right)+\frac{1}{2} E U^{\prime \prime *}\left(a_{1}^{2}\left(r_{1}-i_{1}\right)+g\right)^{2}\right) \\
& =U^{*}+U^{\prime *}\left(a_{0}\left(r_{0}-i_{0}\right)-\left(g+B\left(1+i_{0}\right)\right)\right) \\
& +\frac{1}{2} U^{\prime \prime *}\left(a_{0}\left(r_{0}-i_{0}\right)-\left(g+B\left(1+i_{0}\right)\right)\right)^{2}+E U^{*} \\
& +E U^{\prime *}\left(a_{1}\left(r_{1}-i_{1}\right)+(g+z)\right)+\frac{1}{2} E U^{\prime \prime *}\left(a_{1}\left(r_{1}-i_{1}\right)+(g+z)\right)^{2} \\
& \Rightarrow U^{*}+a_{0} r_{0} U^{\prime *}-a_{0} i_{0} U^{\prime *}-g U^{\prime *}+\frac{1}{2}\left(a_{0}^{2} r_{0}^{2} U^{\prime *}-2 r_{0} i_{0} a_{0}^{2} U^{\prime *}+a_{0}^{2} i_{0}^{2} U^{\prime \prime *}\right. \\
& \left.-2 r_{0} g a_{0} U^{\prime \prime *}+2 i_{0} g a_{0} U^{\prime \prime *}+g^{2} U^{\prime \prime *}\right)+\delta\left(E U^{*}+a_{1} E\left(r_{1} U^{\prime *}\right)-a_{1} i_{1} E\left(U^{\prime *}\right)\right. \\
& +g E\left(U^{\prime *}\right)+\frac{1}{2}\left(a_{1}^{2} E\left(r_{1}^{2} U^{\prime \prime *}\right)-2 i_{1} a_{1}^{2} U^{\prime \prime *}+a_{1}^{2} i_{1}^{2} E\left(U^{\prime \prime *}\right)+2 g a_{0} E\left(r_{1} U^{\prime \prime *}\right)\right. \\
& \left.-2 i_{1} g a_{0} E\left(U^{\prime \prime *}\right)+g^{2} E\left(U^{\prime \prime *}\right)\right)
\end{aligned}
$$




$$
\begin{aligned}
& =U^{*}+U^{\prime *}\left(a_{0} r_{0}-a_{0} i_{0}-g-\left(1+i_{0}\right) B\right)+\frac{1}{2}\left(U^{\prime \prime *}\right)\left(a_{0}^{2} r_{0}^{2}-2 r_{0} i_{0} a_{0}^{2}+a_{0}^{2} i_{0}^{2}\right. \\
& -2 r_{0} g a_{0}+2 i_{0} g a_{0}-2 r_{0} B a_{0}+2 i_{0} B a_{0}-2 r_{0} i_{0} B a_{0}+2 B i_{0}^{2} a_{0}+g^{2}+2 g B\left(1+i_{0}\right) \\
& \left.+B^{2}\left(1+i_{0}\right)^{2}\right)+\delta\left(E U^{\prime *}+a_{1} E\left(U^{\prime *} r_{1}\right)-E\left(U^{\prime *}\right) a_{1} i_{1}+E\left(U^{\prime *}\right) g+E\left(U^{\prime *} z\right)\right) \\
& +\frac{1}{2}\left(a_{1}^{2} E\left(r_{1}^{2} U^{\prime \prime *}\right)-2 E\left(r_{1} U^{\prime \prime *}\right) i_{1} a_{1}^{2}+a_{1}^{2} i_{1}^{2} U^{\prime \prime *}+2 E\left(r_{1} z U^{\prime \prime *}\right) a_{1}-2 i_{1} E\left(z U^{\prime \prime *}\right) a_{1}\right. \\
& \left.+E\left(z^{2} U^{\prime \prime *}\right)+2 E\left(r_{0} U^{\prime \prime *}\right) g a_{0}-2 i_{0} g a_{0} U^{\prime \prime *}+g^{2}+2 g E\left(z U^{\prime \prime *}\right)\right) \\
& \Rightarrow U^{*}+a_{0} r_{0} U^{\prime *}-a_{0} i_{0} U^{\prime *}-g U^{\prime *}+\frac{1}{2}\left(a_{0}^{2} r_{0}^{2} U^{\prime *}-2 r_{0} i_{0} a_{0}^{2} U^{\prime *}+a_{0}^{2} i_{0}^{2} U^{\prime \prime *}\right. \\
& \left.-2 r_{0} g a_{0} U^{\prime \prime *}+2 i_{0} g a_{0} U^{\prime \prime *}+g^{2} U^{\prime \prime *}\right)+\delta\left(E U^{*}+a_{1} E\left(r_{1} U^{\prime *}\right)-a_{1} i_{1} E\left(U^{\prime *}\right)\right. \\
& +g E\left(U^{\prime *}\right)+\frac{1}{2}\left(a_{1}^{2} E\left(r_{1}^{2} U^{\prime \prime *}\right)-2 i_{1} a_{1}^{2} E\left(r_{1} U^{\prime \prime *}\right)+a_{1}^{2} i_{1}^{2} E\left(U^{\prime \prime *}\right)+2 g a_{0} E\left(r_{0} U^{\prime \prime *}\right)\right. \\
& \left.-2 i_{0} g a_{0} E\left(U^{\prime \prime *}\right)+g^{2} E\left(U^{\prime \prime *}\right)\right) \\
& =U^{*}+a_{0} r_{0} U^{\prime *}-a_{0} i_{0} U^{\prime *}-g U^{\prime *}-\left(1+i_{0}\right) B U^{\prime *}+\frac{1}{2}\left(a_{0}^{2} r_{0}^{2}-2 r_{0} i_{0} a_{0}^{2}+a_{0}^{2} i_{0}^{2}\right. \\
& -2 r_{0} g a_{0}+2 i_{0} g a_{0}-2 r_{0} B a_{0}+2 i_{0} B a_{0}-2 r_{0} i_{0} B a_{0}+2 B i_{0}^{2} a_{0}+g^{2}+2 g B\left(1+i_{0}\right) \\
& \left.+B^{2}\left(1+i_{0}\right)^{2}\right) U^{\prime \prime *}+\frac{1}{2}\left(a_{1}^{2} E\left(r_{1}^{2} U^{\prime \prime *}\right)-2 i_{1} a_{1}^{2} E\left(U^{\prime \prime *} r_{1}\right)+a_{1}^{2} i_{1}^{2} E U^{\prime \prime *}+2 E\left(U^{\prime \prime *} r_{1} z\right) a_{1}\right. \\
& +\delta\left(E\left(U^{*}\right)+a_{1} E\left(r_{1} U^{\prime *}\right)-a_{1} i_{1} E\left(U^{\prime *}\right)+g E\left(U^{\prime *}\right)+E\left(z U^{\prime *}\right)-2 i_{1} E\left(z U^{\prime \prime *}\right) a_{1}\right. \\
& \left.\left.+E\left(U^{\prime \prime *} z^{2}\right)+2 E\left(U^{\prime \prime *} r_{0}\right) g a_{0}-2 i_{0} g a_{0} E\left(U^{\prime \prime *}\right)+g^{2} E\left(U^{\prime \prime *}\right)+2 g E\left(U^{\prime \prime *} z\right)\right)\right) \\
& \Rightarrow U^{*}+a_{0} r_{0} U^{\prime *}-a_{0} i_{0} U^{\prime *}-g U^{\prime *}+\frac{1}{2}\left(a_{0}^{2} r_{0}^{2} U^{\prime *}-2 r_{0} i_{0} a_{0}^{2} U^{\prime *}+a_{0}^{2} i_{0}^{2} U^{\prime \prime *}\right. \\
& \left.-2 r_{0} g a_{0} U^{\prime \prime *}+2 i_{0} g a_{0} U^{\prime \prime *}+g^{2} U^{\prime \prime *}\right)+\delta\left(E U^{*}+a_{1} E\left(r_{1} U^{\prime *}\right)-a_{1} i_{1} E\left(U^{\prime *}\right)\right. \\
& +g E\left(U^{\prime *}\right)+\frac{1}{2}\left(a_{1}^{2} E\left(r_{1}^{2} U^{\prime \prime *}\right)-2 i_{1} a_{1}^{2} E\left(r_{1} U^{\prime \prime *}\right)+a_{1}^{2} i_{1}^{2} E\left(U^{\prime \prime *}\right)+2 g a_{0} E\left(r_{0} U^{\prime \prime *}\right)\right. \\
& \left.-2 i_{0} g a_{0} E\left(U^{\prime \prime *}\right)+g^{2} E\left(U^{\prime \prime *}\right)\right) \\
& =U^{*}+a_{0} r_{0} U^{\prime *}-a_{0} i_{0} U^{\prime *}-g U^{\prime *}-\left(1+i_{0}\right) B U^{\prime *}+\frac{1}{2}\left(a_{0}^{2} r_{0}^{2}-2 r_{0} i_{0} a_{0}^{2}+a_{0}^{2} i_{0}^{2}\right. \\
& -2 r_{0} g a_{0}+2 i_{0} g a_{0}-2 r_{0} B a_{0}+2 i_{0} B a_{0}-2 r_{0} i_{0} B a_{0}+2 B i_{0}^{2} a_{0}+g^{2}+2 g B\left(1+i_{0}\right) \\
& \left.+B^{2}\left(1+i_{0}\right)^{2}\right) U^{\prime \prime *}+\delta\left(E\left(U^{*}\right)+a_{1} E\left(r_{1} U^{\prime *}\right)-a_{1} i_{1} E\left(U^{\prime *}\right)+g E\left(U^{\prime *}\right)+E\left(z U^{\prime *}\right)\right. \\
& +\frac{1}{2}\left(a_{1}^{2} E\left(r_{1}^{2} U^{\prime \prime *}\right)-2 i_{1} a_{1}^{2} E\left(U^{\prime \prime *} r_{1}\right)+a_{1}^{2} i_{1}^{2} E U^{\prime \prime *}+2 E\left(U^{\prime *} r_{1} z\right) a_{1}-2 i_{1} E\left(z U^{\prime \prime *}\right) a_{1}\right. \\
& \left.\left.+E\left(U^{\prime \prime *} z^{2}\right)+2 E\left(U^{\prime \prime *} r_{0}\right) g a_{0}-2 i_{0} g a_{0} E\left(U^{\prime \prime *}\right)+g^{2} E\left(U^{\prime \prime *}\right)+2 g E\left(U^{\prime \prime *} z\right)\right)\right)
\end{aligned}
$$

We thus obtain the following reduced relation after simplification:

$$
\begin{aligned}
& -\left(1+i_{0}\right) B U^{\prime *}-\left(r_{0}-i_{0}\right) B a_{0} U^{\prime \prime *}+\left(1+i_{0}\right) g B U^{\prime \prime *}-\left(r_{0}-i_{0}\right) i_{0} B a_{0} U^{\prime \prime *} \\
& +\frac{1}{2} B^{2}\left(1+i_{0}\right)^{2} U^{\prime \prime *}+\delta E\left(z U^{\prime *}\right)+\left(E\left(r_{1}\right)-i_{1}\right) \delta a_{1} E\left(z U^{\prime \prime *}\right) \\
& +\frac{1}{2} \delta E\left(z^{2} U^{\prime \prime *}\right)+\delta g E\left(z U^{\prime \prime *}\right)=0
\end{aligned}
$$


By multiplying this expression with $\frac{-1}{U^{\prime *}}$, the equality becomes:

$$
\begin{aligned}
& \left(1+i_{0}\right) B \frac{-U^{\prime *}}{U^{\prime *}}-\left(r_{0}-i_{0}\right) B a_{0} \frac{-U^{\prime \prime *}}{U^{\prime *}}+\left(1+i_{0}\right) g B \frac{-U^{\prime \prime *}}{U^{\prime *}}-\left(r_{0}-i_{0}\right) i_{0} B a_{0} \frac{-U^{\prime \prime *}}{U^{\prime *}} \\
& +\frac{1}{2} B^{2}\left(1+i_{0}\right)^{2} \frac{-U^{\prime \prime *}}{U^{\prime *}}+\delta E\left(z \frac{-U^{\prime *}}{U^{\prime *}}\right)+\left(E\left(r_{1}\right)-i_{1}\right) \delta a_{1} E\left(z \frac{-U^{\prime *}}{U^{\prime *}}\right) \\
& +\frac{1}{2} \delta E\left(z^{2} \frac{-U^{\prime \prime *}}{U^{\prime *}}\right)+\delta g E\left(z \frac{-U^{\prime \prime *}}{U^{\prime *}}\right)=0
\end{aligned}
$$

$\frac{-U^{\prime \prime *}}{U^{\prime *}}$ is the Arrow Pratt's risk aversion coefficient $(\rho)$. The expression becomes hence:

$$
\begin{aligned}
& \left(1+i_{0}\right) B-\left(r_{0}-i_{0}\right) B a_{0} \rho+\left(1+i_{0}\right) g B \rho-\left(r_{0}-i_{0}\right) i B a_{0} \rho+\frac{1}{2} B^{2}\left(1+i_{0}\right)^{2} \rho \\
& -\delta E(z)+\left(E\left(r_{1}\right)-i_{1}\right) \delta E(z) a_{1} \rho+\frac{1}{2} \delta E\left(z^{2}\right) \rho+\delta g E(z) \rho=0
\end{aligned}
$$

Assuming $\left(E(z)\left(r_{1}\right)-i_{1}\right)=E(z)\left(E\left(r_{1}\right)-i_{1}\right)$ and multiplying by $\left(r_{0}-i_{0}\right)$ and $\left(r_{1}-i_{1}\right)$, yield the expression below

$$
\begin{aligned}
& \left(1+i_{0}\right) B-\left(r_{0}-i_{0}\right) B a_{0} \rho\left(1+i_{0}\right)+\left(1+i_{0}\right) g B \rho+\frac{1}{2} B^{2}\left(1+i_{0}\right)^{2} \rho-\delta E(z) \\
& +\left(E\left(r_{1}\right)-i_{1}\right) \delta E(z) a_{1} \rho+\frac{1}{2} \delta E\left(z^{2}\right) \rho+\delta g E(z) \rho=0
\end{aligned}
$$

\section{4) Complete model: proof of result (10)}

As in the case of the simple model, we start from the insurance purchase condition to derive the following relation $\left(E\left(r_{1}\right)-i_{1}\right)=f(B)$

$$
\left(E\left(r_{1}\right)-i_{1}\right)=\frac{-B\left(1+i_{0}\right)+a_{0} \rho B\left(r_{0}-i_{0}\right)\left(1+i_{0}\right)-\rho g B\left(1+i_{0}\right)-\frac{1}{2} \rho B^{2}\left(1+i_{0}\right)^{2}+\delta E(z)-\frac{1}{2} \delta \rho E\left(z^{2}\right)+\delta \rho g E(z)}{\delta \rho a_{1} E(z)}
$$

To find the optimal value of $B$ that maximizes the benefit of the credit $\left(E\left(r_{1}\right)-i_{1}\right)$, we perform a partial differentiation.

$$
\begin{aligned}
& \frac{\partial\left[\left(E\left(r_{1}\right)-i_{1}\right)\right]}{\partial B}=0 \\
& \Rightarrow-\left(1+i_{0}\right)+a_{0} \rho\left(r_{0}-i_{0}\right)\left(1+i_{0}\right)-\rho g\left(1+i_{0}\right)-\rho B\left(1+i_{0}\right)^{2}=0
\end{aligned}
$$

We obtain,

$$
\begin{aligned}
& \Rightarrow B=\frac{a_{0} \rho\left(r_{0}-i_{0}\right)\left(1+i_{0}\right)-\rho g\left(1+i_{0}\right)-\left(1+i_{0}\right)}{\rho\left(1+i_{0}\right)^{2}} \\
& \Rightarrow B=\frac{a_{0} \rho\left(r_{0}-i_{0}\right)-\rho g-1}{\rho\left(1+i_{0}\right)}
\end{aligned}
$$

The optimal value of the benefit $B$ of the insurance that maximizes the expected benefit of the credit $\left(E\left(r_{1}\right)-i_{1}\right)$ is given by:

$$
\Rightarrow B^{*}=\frac{a_{0}\left(r_{0}-i_{0}\right)-g}{1+i_{0}}-\frac{1}{\rho\left(1+i_{0}\right)}
$$

